\title{
Avaliação da toxicidade das favas de Stryphnodendron fissuratum (Mimosoideae) em vacas gestantes ${ }^{1}$
}

\author{
Cristiano R. Aguiar-Filho ${ }^{2}$, Raquel F. Albuquerque ${ }^{2}$, Brena P. Rocha², Edson M. Colodel ${ }^{3}$, \\ Ricardo A.A. Lemos ${ }^{4}$, Franklin Riet-Correa ${ }^{5}$, Joaquim Evêncio-Neto ${ }^{6}$ e Fábio S. Mendonça ${ }^{6 *}$
}

\begin{abstract}
Aguiar-Filho C.R., Albuquerque R.F., Rocha B.P., Colodel E.M., Lemos R.A.A., Riet-Correa F., Evêncio-Neto J. \& Mendonça F.S. 2013. [Evaluation of the toxicity of Stryphnodendron fissuratum (Mimosoideae) pods in pregnant cows.] Avaliação da toxicidade das favas de Stryphnodendron fissuratum (Mimosoideae) em vacas gestantes. Pesquisa Veterinária Brasileira 33(5):607-612. Programa de Pós-Graduação em Ciência Veterinária, Universidade Federal Rural de Pernambuco, Recife, PE 52171-900, Brazil. E-mail: mendonca@dmfa.ufrpe.br

To evaluate the toxicity of different concentrations of pods of Stryphnodendron fissuratum to pregnant cows, the pods of this tree were grounded, mixed in a commercial food and given to eight pregnant cows in total doses of $6.5 \mathrm{~g} / \mathrm{kg}, 7.5 \mathrm{~g} / \mathrm{kg}, 9 \mathrm{~g} / \mathrm{kg}$ and $10 \mathrm{~g} / \mathrm{kg}$. The animals that received doses of $6.5 \mathrm{~g} / \mathrm{kg}$ delivered normal calves and those that received $7.5 \mathrm{~g} / \mathrm{kg}$ delivered weak calves that did not survive. Doses of $9 \mathrm{~g} / \mathrm{kg}$ resulted in the birth of an immature calf and another with congenital bilateral distichiasis, corneal opacity, and microphthalmia. Both cows that ingested $10 \mathrm{~g} / \mathrm{kg}$ died, and one of these aborted before death. In the dead cows, the gross and histological lesions of the digestive system and liver were similar to those previously described in S. fissuratum poisoning. No significant lesions were observed in the calves and in the aborted fetus. The phytochemical analysis of methanol extracts from pods of S. fissuratum revealed the presence of soluble tannins, proanthocyanidins, leucoanthocyanidins and the triterpenoid saponin $\beta$-amyrin. Triterpenoid saponins had been associated with the toxicity of Stryphnodendron spp. and Enterolobium spp., which cause clinical signs similar to those observed in the poisoning by $S$. fissuratum. The results presented herein confirmed the toxicity of S. fissuratum to bovines. However, the abortive effects of this plant was not confirmed; thus because the abortion and neonatal deaths could be due to the toxicity of the pods to the cows. New research should be done to demonstrate if $S$. fissuratum is a cause of malformations similar to those observed in one of the calves born from the treated cows.
\end{abstract}

INDEX TERMS: Poisonous plants, Stryphnodendron fissuratum, Mimosoideae, abortion, fetal malformation, plant poisoning, cattle.

\footnotetext{
${ }^{1}$ Recebido em 23 de março de 2013.

Aceito para publicação em 18 de abril de 2013.

${ }^{2}$ Departamento de Medicina Veterinária, Universidade Federal Rural de Pernambuco (UFRPE), Rua Dom Manoel de Medeiros s/n, Dois Irmãos, Recife, PE 52171-900, Brasil.

${ }^{3}$ Depto Clínica Médica Veterinária, Faculdade de Agronomia e Medicina Veterinária, Universidade Federal de Mato Grosso (UFMT), Av. Fernando Correia da Costa s/n, Bairro Coxipó, Cuiabá, MT 78068-900, Brasil.

${ }^{4}$ Faculdade de Medicina Veterinária e Zootecnia, Universidade Federal de Mato Grosso do Sul (UFMS), Av. Senador Filinto Müller 2443, Cx. Postal 549, Campo Grande, MS 79070-900, Brasil.

${ }^{5}$ Hospital Veterinário, Centro de Saúde e Tecnologia Rural (CSTR), Campus de Patos, Universidade Federal de Campina Grande (UFCG), Patos, PB 58700-000, Brasil.

${ }^{6}$ Departamento de Morfologia e Fisiologia Animal (DMFA), UFRPE, Recife, PE.*Autor para correspondência: mendonca@dmfa.ufrpe.br
}

RESUMO.- Com o objetivo de avaliar a toxicidade de diferentes concentrações das favas de Stryphnodendron fissuratum em vacas prenhes, as favas desta árvore foram moídas, misturadas à ração comercial e fornecidas a oito vacas nas doses totais de $6,5 \mathrm{~g} / \mathrm{kg}, 7,5 \mathrm{~g} / \mathrm{kg}, 9 \mathrm{~g} / \mathrm{kg}$ e $10 \mathrm{~g} / \mathrm{kg}$. Os animais que receberam doses de $6,5 \mathrm{~g} / \mathrm{kg}$ pariram bezerros normais e aqueles que receberam $7,5 \mathrm{~g} / \mathrm{kg}$ pariram bezerros fracos que não sobreviveram. Doses de $9 \mathrm{~g} / \mathrm{kg}$ resultaram no nascimento de um bezerro imaturo e de outro bezerro com distiquíase, opacidade congênita das córneas e microftalmia. Ambas as vacas que ingeriram $10 \mathrm{~g} / \mathrm{kg}$ morreram, porém uma vaca abortou antes de morrer. Nas vacas que morreram, as lesões macroscópicas e histológicas do sistema digestivo e fígado foram semelhantes às des- 
critas anteriormente na intoxicação por $S$. fissuratum. Nos bezerros e no feto abortado não foram observadas lesões macroscópicas ou histológicas significantes. A análise fitoquímica dos extratos metanólicos das favas de $S$. fissuratum revelou a presença de taninos hidrossolúveis, proantocianidinas, leucoantocianidinas e da saponina triterpénica $\beta$-amirina. Saponinas triterpénicas têm sido associadas com a toxicidade das favas de Stryphnodendron spp. e Enterolobium spp., que causam sinais clínicos semelhantes aos observados na intoxicação por S. fissuratum. Esta pesquisa confirmou a toxicidade das favas de $S$. fissuratum para bovinos, no entanto não foram confirmados os efeitos abortivos das mesmas, pois o aborto e as mortes neonatais observadas podem ser decorrentes dos efeitos tóxicos da planta nas mães. Novas pesquisas são necessárias para pesquisar se as favas da planta causam malformações semelhantes às observas em um dos bezerros nascidos vivos.

TERMOS DE INDEXAÇÃO: Plantas tóxicas, Stryphnodendron fissuratum, Mimosoideae, aborto, malformação fetal, intoxicação por plantas, bovinos.

\section{INTRODUÇÃO}

A intoxicação natural pelas favas de Stryphnodendron fissuratum tem sido registrada nos Estados de Mato Grosso e Mato Grosso do Sul afetando apenas bovinos (Rodrigues et al. 2005, Lemos et al. 2008, Ferreira et al. 2009). Nessa espécie, provoca uma doença severa, cujos índices de morbidade e letalidade variaram de 0,9 a $25 \%$ e de 15 a $100 \%$, respectivamente (Ferreira et al. 2009). A morte dos animais ocorre principalmente por complicações decorrentes de úlceras multifocais no abomaso, hemorragias gastrintestinais e necrose hepática (Rodrigues et al. 2005, Ferreira et al. 2009, Mendonça et al. 2010).

Em estudos sobre as causas de abortamentos de bovinos na Região Centro-Oeste, a toxidez das favas de S. fissuratum é, por vezes, mencionada por pecuaristas e médicos veterinários como causa de abortos e pelo nascimento de bezerros debilitados que não sobrevivem. As propriedades abortivas das favas dessa planta foram demonstradas em caprinos (Alburquerque et al. 2011) porém, estudos mais abrangentes com bovinos ainda não haviam sido realizados.

O objetivo desta pesquisa foi avaliar a toxicidade de diferentes concentrações das favas de $S$. fissuratum para comprovar se esta planta é responsável por alterações reprodutivas observadas em surtos de intoxicações naturais em bovinos.

\section{MATERIAL E MÉTODOS}

\section{Coleta de favas de Stryphnodendron fissuratum}

As favas maduras de $S$. fissuratum foram coletadas no Município de Rondonópolis, MT, entre os meses de julho e agosto de 2010, diretamente das árvores e do solo. Após coletadas, as favas foram acondicionadas em sacos de pano e mantidas sob refrigeração para posterior utilização no experimento. A classificação do material botânico foi realizada no Herbário Central da Universidade Federal de Mato Grosso.

\section{Animais experimentais}

O grupo experimental consistiu de oito vacas mestiças, com idades entre 24 e 36 meses, clinicamente sadias e em terço médio ou final de gestação. Dois bovinos foram utilizados como controles. 0 diagnóstico de gestação foi feito através de palpação retal de acordo com Dirksen (1993).

Trinta dias antes do início dos experimentos os animais receberam medicação antiparasitária e foram mantidos em um curral coletivo, visando à adaptação e observação clínica prévia. No início da manhã, recebiam ração comercial, suplemento mineral, feno de tifton (Cynodon dactylon) e água ad libitum. Posteriormente, eram mantidos em local sombreado para pastar e recolhidos no fim da tarde. Após o período de adaptação, os animais foram numerados de 1 a 10, de forma casualizada. As favas de $S$. fissuratum foram trituradas e ofertadas aos bovinos misturadas à ração comercial em doses fracionadas por três dias consecutivos, totalizando 6,5g/kg, 7,5g/kg, 9g/kg e 10g/kg (Quadro 1).

\section{Avaliação clínica e necropsia}

Durante o período de adaptação e em todo o período de experimentos, os animais foram submetidos a exames clínicos duas vezes ao dia. As vacas foram avaliadas segundo descreveram Stöber (1993) e Dirksen (1993), quanto ao seu estado geral, comportamento, atitude, apetite, cor das mucosas, vasos espisclerais, temperatura retal, frequências cardíaca e respiratória, forma do abdômen, motilidade retículo-ruminal, exame físico das fezes, aparência da pele e ocorrência de abortamento.

Os bovinos que morreram em consequência da doença foram necropsiados; coletaram-se fragmentos de órgãos da cavidade torácica, abdominal, encéfalo, além de útero e placenta. Os fragmentos destinados ao estudo histopatológico foram fixados em formalina a $10 \%$ tamponada com fosfato a $4 \%$, processados pelos métodos usuais, incluídos em parafina, cortados na espessura de $5 \mu \mathrm{m}$ e corados pela hematoxilina-eosina (HE).

Quadro 1. Idade gestacional das vacas no início do experimento, dose administrada e resultados das intoxicações

\begin{tabular}{|c|c|c|c|c|c|c|c|c|c|}
\hline $\begin{array}{c}\text { Bovino } \\
\text { № Peso } \\
\text { (kg) }\end{array}$ & $\begin{array}{l}\text { Estágio gestacio- } \\
\text { nal no início do } \\
\text { experimento } \\
\text { (semanas) }\end{array}$ & $\begin{array}{l}\text { Dose } \\
\text { diária } \\
\text { (g/kg) }\end{array}$ & $\begin{array}{l}\text { Dose } \\
\text { diária } \\
(\mathrm{g})\end{array}$ & $\begin{array}{c}\text { Dose } \\
\text { total } \\
(\mathrm{g} / \mathrm{kg})\end{array}$ & $\begin{array}{c}\text { Total } \\
\text { ingerido } \\
(\mathrm{kg})\end{array}$ & $\begin{array}{l}\text { Início dos sinais } \\
\text { clínicos após a } \\
\text { intoxicação }\end{array}$ & $\begin{array}{l}\text { Intensidade dos } \\
\text { sinais clínicos }\end{array}$ & $\begin{array}{l}\text { Desfecho da } \\
\text { intoxicação }\end{array}$ & $\begin{array}{l}\text { Desfecho da } \\
\text { gestação }\end{array}$ \\
\hline 1318 & 25 & 2,1 & 667 & 6,5 & 2,067 & $3^{\circ}$ dia & $t^{a}$ & Recuperou-se & Bezerro normal \\
\hline 2440 & 20 & 2,1 & 924 & 6,5 & 2,860 & $3^{\circ}$ dia & + & Recuperou-se & Bezerro normal \\
\hline 3330 & 30 & 2,5 & 825 & 7,5 & 2,475 & $1^{\circ}$ dia & + & Recuperou-se & Bezerro fraco \\
\hline $4 \quad 340$ & 35 & 2,5 & 850 & 7,5 & 2,550 & $2^{\circ}$ dia & + & Recuperou-se & Bezerro fraco \\
\hline 5350 & 35 & 3,0 & 1050 & 9 & 3,150 & $2^{\circ}$ dia & ++ & Recuperou-se & Bezerro imaturo \\
\hline 6440 & 15 & 3,0 & 1320 & 9 & 3,960 & $1^{\circ}$ dia & ++ & Recuperou-se & Malformação fetal \\
\hline 7380 & 10 & 3,3 & 1254 & 10 & 3,800 & $1^{\circ} \mathrm{dia}$ & +++ & Morreu & Aborto \\
\hline 8420 & 15 & 3,3 & 1386 & 10 & 4,200 & $1^{\circ}$ dia & +++ & Morreu & - \\
\hline 9410 & 25 & Controle & - & - & - & - & - & - & - \\
\hline 10420 & 30 & Controle & - & - & - & - & - & - & - \\
\hline
\end{tabular}




\section{IHQ para BVDV}

A IHQ foi realizada para verificar se as alterações reprodutivas foram decorrentes do vírus da diarreia viral bovina (BVDV). Para isto, foram coletadas amostras de orelhas de todos os bezerros de acordo com a técnica descrita por Santos et al. (2011). No feto abortado a IHQ foi realizada em amostras de pulmão, baço, timo e fígado. Para realização da IHQ foi utilizado um anticorpo monoclonal anti-BVDV (15C5 Syracuse, USA), na diluição de 1:500 em PBS. Realizou-se a recuperação antigênica com protease $0,05 \%$ por 15 minutos a $37^{\circ} \mathrm{C}$ e as marcações inespecíficas (background) foram reduzidas pela aplicação de leite desnatado a $5 \%$ por 15 minutos. 0 anticorpo primário foi aplicado durante 50 minutos à temperatura de $37^{\circ} \mathrm{C}$, seguido do anticorpo secundário conjugado a fosfatase alcalina (Dako, USA) por aproximadamente 20 minutos cada, à temperatura ambiente. 0 cromógeno utilizado foi o vermelho permanente (Dako, 0695-code). Como contra-corante foi utilizada hematoxilina por aproximadamente 1 minuto (Schmitz 2006).

\section{Estudo fitoquímico}

Após a coleta, as favas de $S$. fissuratum foram secas em temperatura ambiente $\left(25 \pm 2^{\circ} \mathrm{C}\right)$ durante uma semana. Em seguida, o material foi triturado e reduzido a pó. A extração dos componentes das favas foi feita por infusão metanólica, os extratos foram filtrados e os resíduos re-extraídos. As soluções obtidas neste processo foram destiladas à pressão reduzida em evaporador rotativo a $50 \pm 5^{\circ} \mathrm{C}$, obtendo-se assim o extrato bruto (EBF). Para a prospecção fitoquímica, placas de sílica foram utilizadas. Alíquotas de $10 \mu \mathrm{L}$ do EBF foram submetidas à cromatografia em camada delgada (CCD) para a análise da presença de polifenóis (flavonóides, derivados cinâmicos, cumarinas, fenilpropanoglicosídeos, proantocianidinas condensadas, leucoantocianidinas, taninos gálicos), terpenóides (monoterpenos, sesquiterpenos, diterpenos, triterpenos e esteróides), glicosídeos cardíacos, alcalóides e açúcares redutores (Harbone 1984, Wagner \& Bladt 1996). Para a identificação de saponosídeos foi empregado o teste de afrogenicidade que consiste no aquecimento de $12 \mathrm{~mL}$ do extrato metanólico para a eliminação do solvente. Os extratos secos foram diluídos em tubos de ensaio com água destilada, submetidos à agitação manual por trinta segundos, e posteriormente mantidos em repouso por um período de duas horas (Costa 2001).

\section{RESULTADOS}

\section{Quadro clínico-patológico}

Os resultados dos experimentos estão apresentados no Quadro 1. Os Bovinos que receberam doses de 6,5g/kg (Bovinos 1 e 2) e 7,5g/kg (Bovinos 3 e 4) apresentaram sinais clínicos discretos entre o $1^{\circ}$ e $3^{\circ}$ dia após a administração das favas de Stryphnodendron fissuratum. Os sinais clínicos consistiram em apatia, vasos episclerais ingurgitados, lacrimejamento, anorexia e movimentos ruminais incompletos. No 8o dia de experimento esses bovinos haviam se recuperado totalmente. Ao fim do período de gestação, os Bovinos 1 e 2 pariram bezerros normais e os Bovinos 3 e 4 pariram bezerros fracos (Bezerros 3 e 4) que morreram no 9ํ e 14을 dia pós-parto respectivamente. Não foram observadas lesões significativas nas necropsias nem no estudo histológico destes bezerros.

Os Bovinos que receberam doses de $9 \mathrm{~g} / \mathrm{kg}$ (Bovinos 5 e 6) apresentaram sinais clínicos entre o $1^{\underline{0}}$ e $2^{\underline{0}}$ dias após o término da administração das favas. Além dos sinais previamente descritos, havia desidratação, enoftalmia, timpa- nismo, anorexia, movimentos ruminais incompletos e fezes pastosas contendo muco, estrias de sangue e sementes da planta. Os bovinos também apresentavam agressividade, polidipsia, dismetria e permaneciam por longos períodos com o alimento na boca sem movimentos de mastigação. No 7o dia de experimento, o Bovino 5 pariu precocemente um bezerro imaturo (Bezerro 5) e se recuperou totalmente no $22^{\circ}$ dia. 0 Bezerro 5 apresentava pelagem completa, porém curta e de espessura fina; a pelagem da barbela, barriga e umbigo também era rarefeita, curta e eriçada. Os dentes incisivos e os cascos apresentavam menor grau de desenvolvimento. 0 Bovino 6 se recuperou completamente no $26^{\circ}$ dia de experimento e pariu um bezerro fraco (Bezerro 6) com distiquíase, opacidade congênita das córneas e microftalmia (Fig.1A e 1B). À necropsia desse bezerro não havia outras más formações.

Os Bovinos que receberam doses de $10 \mathrm{~g} / \mathrm{kg}$ (Bovinos 7 e 8) apresentaram os primeiros sinais clínicos no $1^{\text {o }}$ dia após o fim da administração das favas. Os sinais foram intensos e consistiram em fraqueza, bruxismo, ataxia, dismetria, distasia, desidratação acentuada e sialorreia devido à presença de erosões e úlceras na mucosa oral e do palato. No $5^{\circ}$ dia de experimento, o Bovino 7 apresentou tremores de cabeça, respiração ruidosa, diarréia líquida, atonia ruminal e decúbito esternal prolongado. Ocorreu aborto no 50 dia após o consumo da planta e morte no 7ํ dia de experimento. Á necropsia do feto abortado havia áreas difusas de hemorragias petequio-equimóticas na pele (Fig.1C). Não foram observadas lesões histológicas significantes. O Bovino 8 apresentou sinais clínicos similares aos observados no Bovino 7, porém não houve aborto. A morte ocorreu no $5^{0}$ dia após a ingestão da planta.

A imunohistoquímica não mostrou marcação para diarreia viral bovina em nenhum bezerro ou no feto abortado. Não foram encontradas alterações histológicas significativas nas placentas das vacas que ingeriram a planta assim como nas placentas das vacas do grupo controle. Nos bovinos que morreram, os principais achados de necropsia consistiram em úlceras na mucosa do palato (Fig. 1D) e esôfago, além de hiperemia na mucosa do rúmen, retículo e omaso. No abomaso havia hemorragia e necrose difusa da mucosa. As alças intestinais estavam distendidas e intensamente avermelhadas e continham significativa quantidade de muco. 0 ceco apresentava-se dilatado, com um conteúdo pastoso escuro e com estrias de sangue. Os linfonodos mesentéricos estavam aumentados de volume e edematosos ao corte. 0 fígado estava aumentado de volume, congesto, com aumento do padrão lobular e com a vesícula biliar distendida. Os rins estavam ligeiramente aumentados de volume e congestos. Os demais órgãos não apresentaram lesões significativas. Histologicamente havia degeneração, espongiose, presença de células acantolíticas e necróticas na mucosa do rúmen, retículo e omaso. Derrame serofibrinoso e reação inflamatória ocorreram principalmente nas áreas de úlceras do rúmen e na mucosa do duodeno. No intestino grosso ocorreram alterações discretas na lâmina própria que consistiram em edema, secreção fibrinosa e congestão de capilares. No fígado havia marcado edema de hepatócitos, vacuolização hepatocelular, focos individuais 

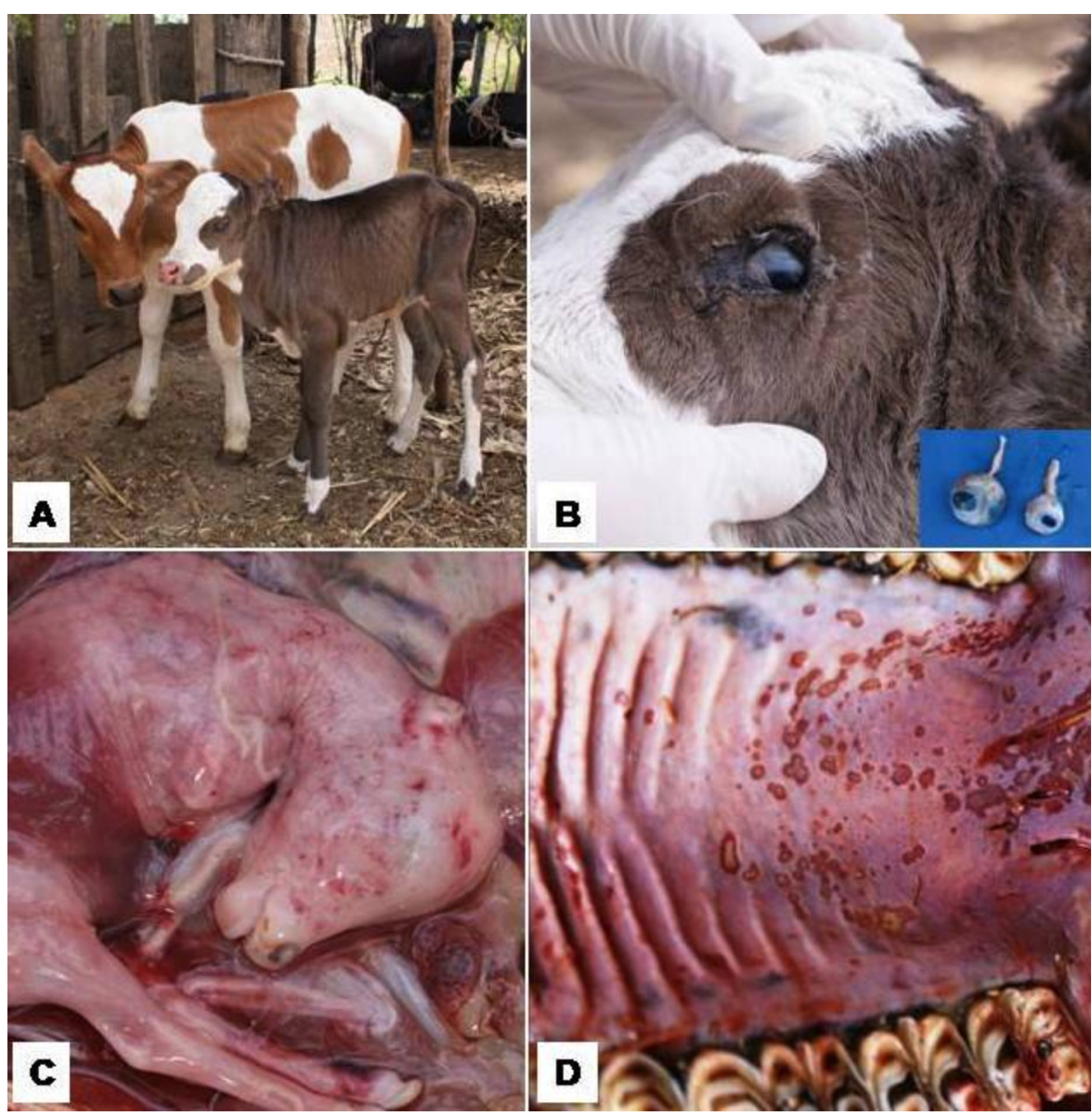

Fig.1. Intoxicação por Stryphnodendron fissuratum em bovinos. (A) Bezerro 9 (esquerda), utilizado como controle, aos 65 dias de vida e bezerro 6 (direita), (B) com 60 dias de vida com desenvolvimento retardado, distiquíase, opacidade congênita da córnea e microftalmia (inset). (C) Feto abortado cuja mãe consumiu $9 \mathrm{~g} / \mathrm{kg}$ das favas da planta, com áreas difusas de hemorragias cutâneas petequio-equimóticas. (D) Úlceras difusas na mucosa do palato em bovino intoxicado com $9 \mathrm{~g} / \mathrm{kg}$ das favas de S. fissuratum.

Quadro 2. Estudo fitoquímico das favas de Stryphnodendron fissuratum por cromatografia em camada delgada

\begin{tabular}{lc}
\hline \multicolumn{1}{c}{ Metabólitos secundários } & Resultado das reações \\
\hline O-glicosídeos de canferol & $-^{\mathrm{a}}$ \\
Quercetina - & + \\
Taninos hidrossolúveis & \\
Cumarinas - & ++ \\
Proantocianidinas & + \\
Leucoantocianidinas & - \\
Derivados gálicos e elágicos & - \\
Ácido clorogênico & - \\
Glicosídeos de luteolina & \\
Álcalóides - & + \\
Triterpenos ( $\beta$-amirina) & \\
\hline
\end{tabular}

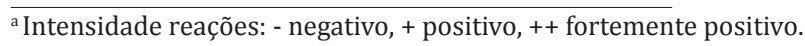

e aleatoriamente distribuídos de necrose hepatocelular e colestase. Nos rins, as alterações foram discretas e consistiram em necrose epitelial tubular com depósitos ocasionais de material eosinofílico no lúmen dos túbulos renais. Lesões no sistema nervoso central foram identificadas no córtex, mesencéfalo e tronco cerebral e consistiram em leve espongiose da substância branca.

\section{Estudo fitoquímico}

A análise fitoquímica dos extratos metanólicos das favas de Stryphnodendron fissuratum revelou a presença de taninos hidrossolúveis, proantocianidinas, leucoantocianidinas e a saponina triterpenóide $\beta$-amirina (Quadro 2).

\section{DISCUSSÃO}

Esta pesquisa confirmou a toxicidade das favas de $S$. fissuratum para bovinos, com sinais clínicos e lesões semelhantes aos relatados anteriormente (Rodrigues et al. 2005, Lemos et al. 2008, Ferreira et al. 2009); no entanto, não foram confirmados os efeitos abortivos das mesmas, já que o aborto e as mortes neonatais observadas podem ter sido consequência dos efeitos tóxicos da planta nas mães. Novas pesquisas são necessárias para pesquisar se as favas da planta causam malformações semelhantes às observas em um dos bezerros nascidos vivos.

Na região Centro-Oeste do Brasil, o consumo de favas de um grupo de árvores leguminosas da subfamília Mimosoideae, família Fabaceae durante a estação seca do ano, incluindo Enterolobium contortisiliquum (Grecco et al. 2002; Mendonça et al. 2009; Lemos et al. 2011), Enterolobium gummiferum (Deutsch et al. 1965), e Stryphnodendron 
obovatum (Brito et al., 2001ab) têm sido associados com alterações digestórias, fotossensibilização, abortos e mortandade de bovinos (Tokarnia et al. 2012) semelhantes às causadas por $S$. fissuratum (Rodrigues et al. 2005, Lemos et al. 2008, Ferreira et al. 2009).

Várias substâncias isoladas das favas de $S$. fissuratum podem ter relação com o quadro clínico-patológico da intoxicação. Os taninos hidrossolúveis (THs) estão presentes em várias leguminosas arbóreas tropicais e sua toxicidade ocorre devido à sua transformação em substâncias absorvíveis de baixo peso molecular pela microfauna ruminal e posterior absorção gástrica. As principais lesões provocadas por THs são gastroenterite hemorrágica e necrose hepática e dos túbulos contorcidos proximais renais (Reed 1995). Proantocianidinas (PAs) e leucoantocianidinas (LAs) são taninos condensados não absorvíveis, porém, apesar disso, podem provocar lesões no trato gastrointestinal por prejudicarem a absorção de nutrientes e reduzindo a absorção dos aminoácidos metionina e lisina. 0 decréscimo nos níveis de metionina pode provocar intoxicação por glicosídeos cianogênicos porque este aminoácido está envolvido na detoxificação dos cianideos via metilação de tiocianatos (Haslam 1989). Porém, não há evidências científicas que os taninos hidrossolúveis ou condensados sejam primariamente responsáveis pelas alterações observadas nos bovinos deste estudo.

As alterações causadas por $S$. fissuratum se devem possivelmente aos efeitos tóxicos de saponinas. Saponinas triterpenoides foram isoladas anteriormente de $S$. fissuratum (Haraguchi et al. 2006, Yokosuka et al., 2008). Diferentes tipos de saponinas foram identificadas em E. contortisiliqquum; destas, enterolosaponina A e contortisilioside B resultaram tóxicas para macrófagos e linfoma murino (Mimaki et al. 2003, 2004). Saponinas de E. gummiferum foram associadas a hepatotoxicidade e abortos em cobaias (Carvalho et al. 1981, Bonel-Raposo et al. 2008). Neste trabalho a única saponina identificada foi $\beta$-amirina. Propriedades abortivas, antizigóticas e efeitos deletérios sobre a implantação de embriões de animais foram também associadas às saponinas contidas em Phytolacca dodecandra (Stolzenberg \& Parkhurst 1976), Costus speciosus (Tewary et al. 1973) e Gutierrezia sarothrae (Knight \& Walter 2001). Em ratas, o extrato butanólico de Mussaenda pubescens, que contém significativa quantidade de saponinas, induziu o nascimento de crias prematuras e fracas (Quin \& Xu 1998).

Em um trabalho anterior, as favas de $S$. fissuratum causaram aborto em cabras (Albuquerque et al. 2011); porem neste trabalho com bovinos pareceria que os abortos e a mortalidade neonatal as alterações fetais ocorreram em consequência da toxicidade da planta nas mães. Existem diversas plantas no Brasil, que pelo fato de produzirem graves alterações em órgãos como rim e fígado das vacas que as ingerem, induzem ao aborto em função da toxemia, como por exemplo, Lantana glutinosa (Riet-Correa et al. 1984) e Amaranthus spinosus em ovinos (Peixoto et al. 2003).

A observação de malformações oculares em um dos bezerros nascidos, que resultou negativo para o vírus da diarreia viral bovina sugere a possibilidade de que as favas de S. fissuratum tenham causado essa malformação. Diversas plantas, incluindo Astragalus lentiginosus, Conium maculatum, Lupinus spp, Nicotiana glauca, Nicotiana tabacum, Oxytropis spp., Veratrum californicum (Keeler 1990, Cheeke 1998, Gardner et al. 1998, Panter et al. 2000, 2011, James et al. 2004) e Mimosa tenuiflora (Pimentel et al. 2007), causam malformações em ruminantes. Os principais teratógenos descritos nessas plantas são alcalóides indolizidínicos, piperidínicos e quinolizidinicos (Keeler 1984, Panter et al. 1994). Os resultados das análises fitoquímicas das favas de S. fissuratum quanto à presença de alcalóides foram negativos (Quadro 2). Estudos adicionais sobre as propriedades teratogênicas das toxinas contidas nas favas de S. fissuratum devem ser realizados.

Agradecimentos.- Trabalho financiado pelo Instituto Nacional de Ciência e Tecnologia para o Controle das Intoxicações por Plantas (Proc. CNPq no. 573534/2008-2) e pela FAPEMAT (Proc. no. 449313/2009).

\section{REFERÊNCIAS}

Albuquerque R.F., Evêncio-Neto J., Freitas S.H., Dória R.G.S., Saurini N.O., Colodel E.M., Riet-Correa F. \& Mendonça F.S. 2011. Abortion in goats after experimental administration of Strypnhodendron fissuratum (Mimosoideae). Toxicon 80:602-605.

Bonel-Raposo J., Riet-Correa F., Guim T.N., Schuch I.D., Grecco F.G. \& Fernandes C.G. 2008. Intoxicação aguda e abortos em cobaias pelas favas de Enterolobium contortisiliquum (Leg. Mimosoideae). Pesq. Vet. Bras. 28:593-596.

Brito M.F., Tokarnia C.H., Peixoto P.V., Silva H.K. \& Nogueira M. 2001a. Intoxicação experimental pelas favas de Stryphnodendron obovatum (Leg. Mimosoideae) em bovinos. 1. Caracterização do quadro clínico. Pesq. Vet. Bras. 21:9-17.

Brito M.F., Tokarnia C.H. \& Peixoto P.V. 2001b. Intoxicação experimental pelas favas de Stryphnodendron obovatum (Leg. Mimosoideae) em bovinos. 2. Achados anátomo e histopatológicos. Pesq. Vet. Bras. 21:61-71.

Costa A.F. 2001. Farmacognosia. Vol.3. 3ª ed. Fundação Calouste Gulbenkian, Lisboa. 1032p.

Carvalho L.R. 1981. Estudos químico e biológico de uma saponina de Enterolobium gummiferum. Dissertação de Mestrado, Universidade de São Paulo, São Paulo. 83p.

Cheeke P.R. 1998. Natural Toxicants in Feeds, Forages, and Poisonous Plants. $2^{\text {nd }}$ ed. Interstate Publishers, Danville, p.691-699.

Deutsch J., Döbereiner J. \& Tokarnia C.H. 1965. Fotossensibilidade hepatogênica em bovinos na intoxicação pela fava de Enterolobium gummiferum. Anais IX Congr. Int. Pastagens, São Paulo, p.1279-1282.

Dirksen G., Gründer H.D., Stöber M. \& Rosenberger 1993. Exame Clínico dos Bovinos. $3^{\mathrm{a}}$ ed. Guanabara Koogan, Rio de Janeiro. 419p.

Ferreira E.V., Boabaid F.M., Arruda L.P., Lemos R.A.A., Souza M.A., Nakazato L. \& Colodel E.M. 2009. Intoxicação por Stryphnodendron fissuratum (Mimosoideae) em bovinos. Pesq. Vet. Bras. 29:951-957.

Gardner D.R., Panter K.E., Stegelmeier B.L., James L.F., Ralphs M.H., Pfister J.A. \& Schoch T.K. 1998. Livestock poisoning by teratogenic and hepatotoxic range plants, p.303-306. In: Garland T. \& Barr A.C. (Eds), Toxic Plants and Other Natural Toxicants. CAB International, Wallingford, UK. $585 p$.

Grecco F.B., Dantas A.F.M., Riet-Correa F., Leite C.G.D. \& Raposo J.B. 2002. Cattle intoxication from Enterolobium contortisiliquum pods. Vet. Human Toxicol. 44:160-162.

Haraguchi M., Yokosuka A., Kawakami S., Chaves N.S.T., Brum K.B., Raspantini P.C., Górniak S.L. \& Mimaki Y. 2006. Nuevas saponinas aisladas de las vainas del Stryphnodendron fissuratum. Labciencia 3:6-8.

Harbone J.B. 1984. Phytochemical methods: a guide to modern techniques of plant analysis. Chapman and Hall, London. 216p.

Haslam E. 1989. Plant Polyphnols: vegetable tannins revised. Cambridge University Press, Cambridge, UK, p.91-100. 
James L.F., Panter K.E., Gaffield W. \& Molyneux R.J. 2004. Reviews: bio medical applications of poisonous plant research. J. Agric. Food Chem. 52:3211-3230.

Keeler R.F. 1984. Teratogens in plants. J. Anim. Sci. 58:1029-1039.

Keeler R.F. 1990. Early embryonic death in lambs induced by Veratrum californicum. Cornell Vet. 80:203-207.

Knight A.P. \& Walter R.G. 2001. A Guide to Plant Poisoning of Animals in North America. Teton New Media., Jackson, WY. 367p.

Lemos R.A., Purisco L., Nakazato L. \& Dutra I.S. 1998. Intoxicação por Enterolobium contortisiliquum, p.307-312. In: Lemos R.A.A. (Ed.), Principais Enfermidades de Bovinos de Corte do Mato Grosso do Sul. Universidade Federal do Mato Grosso do Sul, Campo Grande, MS.

Lemos R.A.A., Guilherme D.J. \& Gonçalves Júnior W. 2008. Intoxicação por Stryphnodendron fissuratum, p.287-289. In: Lemos R.A.A. \& Leal C.R.B. (Eds), Doenças de Impacto Econômico em Bovinos de Corte: perguntas e respostas. Vol.1. UFMS, Campo Grande, MS.

Mendonça F.S., Evêncio-Neto J., Evêncio L.B., Dória R.G.S., Freitas S.H., Pelegrini L.F., Cruz R.A.S., Ferreira E.V. \& Colodel E.M. 2009. Natural and experimental poisoning of cattle by Enterolobium contortisiliquum pods (Fabaceae Mimosoideae) in Central-Western Brazil. Acta Vet. Brno 78:621-625

Mendonça F.S., Evêncio-Neto J., Estevão L.R.M., Melo L.E.H., Freitas S.H., Arruda L.P., Boabaid F.M. \& Colodel E.M. 2010. Aspectos clínicos da intoxicação experimental pelas favas de Stryphnodendron fissuratum (Leg. Mimosoideae) em caprinos. Pesq. Vet. Bras. 30:203-210.

Mimaki Y., Harada H., Sakuma C., Haraguchi M., Yui S., Kudo T., Yamazaki M. \& Sashida Y. 2003. Enterolosaponins A and B, novel triterpene bisdesmosides from Enterolobium contortisiliquum, and evaluation for their macrophage-oriented cytotoxic activity. Bioorg. Med. Chem. Letters 13:623-627.

Mimaki Y., Harada H., Sakuma C., Haraguchi M., Yui S., Kudo T., Yamazaki M. \& Sashida Y. 2004. Contortisiliosides A-G: isolation of seven new triterpene bisdesmosides from Enterolobium contortisiliquum and their cytotoxic activity. Helvetica Chimica Acta 87:851-865.

Panter K.E., James L.F., Gardner D.R. \& Molyneux R.J. 1994. The effects of poisonous plants on embryonic and fetal development in livestock, p.325-332. In: Colegate S.M. \& Dorling P.R. (Eds), Plant Associated Toxins. CAB International, Wallingford, UK. 581p.

Panter K.E., Weinzweig J., Gardner D.R., Stegelmeier B.L. \& James L.F. 2000. Comparison of cleft palate induction by Nicotiana glauca in goats and sheep. Teratology 61:203-210.

Panter K.E., Wlech K.D., Lee S.T., Gardner D.R., Steegelmeier B.L., Ralphs M.H., Davis T.Z., Green B.T., Pfister J.A. \& Cook D. 2011. Plants teratogenic to livestock in the United States, p.236-242. In: Riet Correa F., Pfister
J., Schild A.L. \& Wierenga T. (Eds), Poisoning by Plants, Mycotoxins and Related Toxins. CAB International, Wallingford, UK. 739p.

Peixoto P.V., Brust L.A.C., Brito M.F., França T.N., Cunha B.R.M. \& Andrade G. B. 2003. Intoxicação natural por Amaranthus spinosus (Amaranthaceae) em ovinos no Sudeste do Brasil. Pesq. Vet. Bras. 23:179-184.

Pimentel L.A., Riet Correa F., Gardner D., Panter K.E., Dantas A.F.M., Medeiros R.M.T., Mota R.A. \& Araújo J.A.S. 2007. Mimosa tenuiflora as a cause of malformations in ruminants in the northeastern Brazilian semiarid rangelands. Vet. Pathol. 44:928-931.

Quin G.W \& Xu R.S. 1998. Recent advances in bioactive natural products from Chinese medicinal plants. Med. Res. Rev. 18:375-382.

Reed J.D. 1995. Nutritional toxicology of tannins and related polyphenols in forage legumes. J. Anim. Sci. 73:1516-1528.

Riet-Correa F., Méndez M.C., Schild A.L., Riet-Correa I. \& Silva Neto S.R. 1984. Intoxicação por Lantana glutinosa (Verbenaceae) em bovinos no estado de Santa Catarina. Pesq. Vet. Bras. 4:147-153.

Rodrigues A.S., Chaves N.S.T., Damasceno A.D., Trindade B.R., Martins G.H.L. \& Arantes A.F. 2005. Aspectos clínicos da intoxicação experimental de bovinos pelos frutos de Stryphnodendron fissuratum Mart. ("rosquinha"). Ciênc. Anim. Bras. 6:119-126.

Santos A.S., Antoniasse N.A.B., Boabaid F.M., Bitencourt A.P.G., Almeida L.L., Canal C.W., Flores E.F. \& Driemeier D. 2011. Aspectos clínicos, patológicos, imuno-histoquímicos e virológicos em cinco bezerros persistentemente infectados com o vírus da diarreia viral bovina em uma propriedade do Rio Grande do Sul. Pesq. Vet. Bras. 31:885-892.

Schmitz M. 2006. Caracterização patológica e imunoistoquímica da infecção pelo vírus da diarréia viral bovina. Dissertação de Mestrado em Patologia Animal, Faculdade de Medicina Veterinária, Universidade Federal do Rio Grande do Sul, Porto Alegre, RS. 63p.

Stöber M. 1976. Identificação, anamnese, regras básicas da técnica de exame clínico geral, p.44-80. In: Dirksen G., Gründer H.D. \& Stöber M. (Eds), Exame Clínico dos Bovinos. 3 a ed. Guanabara Koogan, Rio de Janeiro.

Stolzenberg S.J. \& Parkhurst R.M. 1976. Blastocidal and contraceptive actions by an extract and compounds from endod (Phytolacca dodecandra). Contraception 14:39-51.

Tewary P.V., Chaturvedi C. \& Pandey V.B. 1973. Antifertility activity of Costus speciosus $\mathrm{Sm}$. Indian J. Pharmacol. 35:114-115.

Tokarnia C.H., Döbereiner J. \& Peixoto P.V. 2012. Plantas Tóxicas do Brasil. $2^{\underline{a}}$ ed. Editora Helianthus, Rio de Janeiro. 366p.

Wagner H. \& Bladt S. 1996. Plant drug analysis: a thin layer chromatography atlas. $2^{\text {nd }}$ ed. Springer Verlag, Berlim. 384p.

Yokosuka A., Kawakami S., Haraguchi M. \& Yoshihiro M. 2008. Stryphnosides A-F, six new triterpene glycosides from the pericarps of Stryphnodendron fissuratum. Tetrahedron 64:1474-1481. 